\title{
Electrical cardioversion for persistent atrial fibrillation after treatment of thyrotoxicosis
}

\author{
P. EMERY* \\ M.A., M.R.C.P.
}

\author{
J. S. STAFFURTH \\ M.D., F.R.C.P.
}

Lewisham Hospital, Lewisham High Street, Lewisham SE13

\begin{abstract}
Summary
A review of 22 patients with atrial fibrillation after the treatment of thyrotoxicosis, who underwent elective electrical cardioversion, showed that only $45 \%$ were still in sinus rhythm at 2 years and $36 \%$ in the long term (mean 7.4 years). There were no significant differences in factors assessed between those persisting in sinus rhythm and in those who relapsed. A delay in the initial curative treatment of thyrotoxicosis may be a factor in influencing the outcome.

\section{Introduction}

Electrical cardioversion (EC) has been used to treat atrial fibrillation (AF) since 1962. Because of initial high relapse rates it is now used more selectively for patients in whom a reversible cause such as thyrotoxicosis has been treated. We report here an analysis of the long-term results of EC given to patients with persistent AF after the successful treatment of thyrotoxicosis, five of whom were taking thyroxine for hypothyroidism.
\end{abstract}

\section{Materials and methods}

A consecutive series of 22 patients has been analysed, 15 being seen personally, with respect to their cardiac state. Ten were male, 14 had been treated with ${ }^{131} I$ and eight by subtotal thyroidectomy.

\section{Results}

Of the 22 subjects, two failed to respond to EC or relapsed within $24 \mathrm{hr}, 12(55 \%)$ were in sinus rhythm at one year, $10(45 \%)$ at 2 years and only eight $(36 \%)$ were still in sinus rhythm at the time of follow-up (mean 7.4 years). Of those who relapsed in the first 12 months, four did so in the first 3 months, three in the second and three in the last 6 months. Relapse of AF was associated with relapse of thyrotoxicosis in only

\footnotetext{
*Present address: Dept. of Rheumatology, Guy's Hospital, London SEl
}

one patient (as described later). Further analysis, with a comparison of the patients who relapsed and those still in sinus rhythm at 2 years is shown in Table 1. There were no significant differences in the factors assessed between the groups. An adverse factor such as hypertension, ischaemic heart disease, abnormal chest X-ray after treatment and electrocardiographic abnormalities was present in seven patients of those in sinus rhythm and in six of those in AF; three patients of each group had two such adverse factors.

Many of the subjects were extremely grateful for EC, and three who relapsed specifically asked for this treatment again, in only one of whom, however, was it successful for more than a few weeks. One subject was only 18 years old when he had a thyroidectomy for severe thyrotoxicosis. Atrial fibrillation developed 5 years later, probably as a result of unrecognized continued thyrotoxicosis, final cure of which did not occur for another 5 years. Atrial fibrillation persisted for these 5 years and when EC was finally performed it was successful for only 6 months before he developed AF again. Full investigation, including echocardiography, failed to reveal any other cause.

Early patients did not receive prophylactic anticoagulants and one subject had a transient hemiplegia due to an embolus within 24 hours of EC, but fortunately she made a complete recovery. Later patients were anticoagulated orally before EC without any complication; no drug prophylaxis was used after EC to prevent relapse.

Most of the patients with persistent AF were asymptomatic when the heart rate was controlled with digoxin. Only one subject with persistent AF, had a significant disability, a labourer who was unable to perform his heavy work, and who has now had four cardioversions!

\section{Discussion}

These results in treated thyrotoxicosis are disap- 
TABLE 1. Comparison of 10 patients in sinus rhythm with 12 in atrial fibrillation (AF) two years after electrical cardioversion (EC)

\begin{tabular}{lll}
\hline & \multicolumn{1}{c}{ Sinus rhythm } & Atrial fibrillation \\
\hline Number & 10 & 12 \\
Mean age & $57 \cdot 1$ years (range 49-74) & 53.6 years (range 19-65) \\
Male & $4(40 \%)$ & $6(50 \%)$ \\
AF at diagnosis of thyrotoxicosis & $6^{*}(60 \%)$ & $11+(91 \%)$ \\
$\begin{array}{l}\text { Mean time from first diagnosis of } \\
\text { thyrotoxicosis until EC }\end{array}$ & 51 months (range 2-180) & 46.5 months (range 6-156) \\
$\begin{array}{l}\text { Mean duration of AF before EC } \\
\text { Carbimazole treatment on a }\end{array}$ & 19.6 months (range 2-72) & 30.8 months (range < 1-158) \\
$\quad$ previous occasion & $7(70 \%)$ & $9(75 \%)$ \\
\hline
\end{tabular}

*The other four patients developed AF between 33 and 174 months after diagnosis.

†The other patient developed AF 33 months after diagnosis.

pointing, particularly as the patients were all less than 65 years old, and the initiating cause had been treated. Our results are similar to other reports of EC in patients in whom thyrotoxicosis had been treated, which show relapse rates of AF at 15 months of $60 \%$ (Szekely, Batson and Stark, 1966), and at 2 years of 65\% (Radford and Evans, 1968), and 71\% (Waris, Kreus and Solakannel, 1971). In our cases there was no significant difference between those still in sinus rhythm at 2 years and those who had relapsed, in respect of age, length of time that AF had been present, and the number with adverse factors. However, the period of time in AF before EC is almost certainly an under-estimate, as half the patients were unable to recall the exact onset. This under-estimation is likely to be greater in the patients who relapsed, for a greater number of them were in $\mathrm{AF}$ at the time of their original diagnosis.

What is striking in all cases is the very long interval both from the time when thyrotoxicosis was first diagnosed and AF was first recorded, before EC was undertaken. This was mainly because $16(73 \%)$ had been treated with a course of carbimazole when they first presented and had subsequently relapsed. One of us has noted elsewhere that there is a much greater likelihood of spontaneous reversion to sinus rhythm if thyrotoxicosis complicated by AF is treated promptly and definitively with curative treatment when first seen (Staffurth, Gibberd and Hilton, 1965; Staffurth, 1976). As a result, we have not needed to perform EC so frequently in the last few years.

Staffurth et al. (1965) and Symons (1979) believe that thyrotoxicosis may cause permanent damage to the heart which is more likely when there is delay in treatment. Davis and Pomerance (1972) reported an apparent loss of muscle fibres in the sinoatrial node in patients dying in AF, which might well obtain in thyrotoxicosis, though there is no direct evidence in this condition. The young man reported above with a very long history of thyrotoxicosis and AF is particularly noticeable in this respect.

Prophylactic anti-arrhythmic drugs were not given, there being little evidence at the time when most patients were treated that drugs then available were effective. There was also the assumption that, as the precipitating cause of AF had been treated, relapse to AF was unlikely. Prophylaxis with the more effective modern drugs, such as disopyramide and amiodarone might have influenced the four early relapses (within 3 months). But, as $75 \%$ of relapses were spread over the subsequent 21 months (and continued over the follow-up period), drug treatment would need to have been prolonged, with its own disadvantages, to have been effective.

Oral anticoagulants were given prophylactically to patients before EC in the latter half of the study. There is a significant risk of embolism in thyrotoxicosis complicated by AF especially when this is associated with heart failure (Staffurth, Gibberd and $\mathrm{Ng}$ Tang Fui, 1977; Hurley et al., 1981), so we now consider that most of the patients should be anticoagulated when first seen.

This review has shown a disappointing number of relapses in the middle- and long-term. Relapse did not appear to be related to the presence or absence of associated heart diseases, or to the length of time that AF had been present, but there is an indication that earlier curative treatment would have prevented the onset of AF in many subjects. We therefore recommend strongly that curative treatment should invariably be given to all thyrotoxic patients who have AF when first seen. Most patients were very grateful for EC so we feel it should be offered to all under 65 years. But in view of the number who relapse, it should not be pressed on those who are unwilling for it to be performed.

\section{References}

Davies, M.J. \& Pomerance, A. (1972) Pathology of atrial fibrillation in man. British Heart Journal, 34, 520.

HuRley, D.M., Hunter, A.N., HewitT, M.J. \& Stockigt, J.R. (1981) Atrial fibrillation and arterial embolism in hyperthyroidism. Australian and New Zealand Journal of Medicine, 11, 391. 
RADFORD, M.D. \& Evans, D.W. (1968) Long-term results of D.C. reversion of atrial fibrillation. British Heart Journal, 30, 91.

STAFFURTH, J.S. (1976) Communication to Thyroid Club.

Staffurth, J.S., Gibberd, M.C. \& Hilton, P.J. (1965) Atrial fibrillation in thyrotoxicosis treated with radioiodine. Postgraduate Medical Journal, 41, 663.

STAFfurTh, J.S., GibBerd, M.C. \& NG TANG Fui, S. (1977) Arterial embolism in thyrotoxicosis with atrial fibrillation. British Medical Journal, 2, 688.
Symons, C. (1979) Thyroid heart disease. British Heart Journal, 41, 257.

SZekely, P., Batson, G.A. \& STARK, D.C.C. (1966) Direct current shock therapy of cardiac arrhythmias. British Heart Journal, 28, 366.

WARIS. E., KREUS, K.E. \& SolaKanNEL, J. (1971) Factors influencing persistence of sinus rhythm after D.C. shock treatment of atrial fibrillation. Acta medica Scandinavica, 189, 161. 